hand, common and may be profuse. A bronchial carcinoma usually produces changes in the lungs that are easily seen in a film, but the small benign growth will not be detected unless it is large enough to block the lumen and cause atelectasis. It follows, therefore, that the radiological examination may be entirely negative. Examples of such cases were described by Morlock and Scott Pinchin (1935), McGibbon and Baker-Bates (1937), and others. The latter authors describe tracheal varix and non-specific granuloma as causes of pulmonary haemorrhage. The rare tracheal carcinoma may be the cause of haemoptysis, and is sometimes visible in the skiagram after lipiodol. If the radiological examination is negative and the attacks of haemoptysis continue, a bronchoscopic examination must be considered.

\section{Aneurysm of the Aorta}

In aneurysm of the aorta haemoptysis is only seen as a terminal event, staining of the sputum being a warning sign of the imminence of a rupture. The diagnosis of aneurysm is not always easy to the clinician, especially if the posterior part of the arch or the descending thoracic aorta is involved. Unfortunately it is not always simple for the radiologist, for any growth or tumour in the neighbourhood of the aorta will simulate an aneurysm, especially if the growth is one in close contact with the aortic arch and involving the pericardium. Mistakes often occur, and the Wassermann reaction is not an infallible test. Aneurysm may simulate a dermoid cyst if it is directed forwards and laterally in the superior mediastinum. Kymography is of great assistance in such cases, and I think that in the future it should lead to a correct diagnosis in most cases, since it enables us to separate the outline of the aorta from the growth and usually gives a characteristic picture.

\section{Haemoptysis following Injury to Chest}

Haemoptysis may follow injuries to the chest with or without rib fracture. Where the injury is severe the presence of a fracture is very easily shown, but there are many cases where radiological demonstration of a fractured rib is difficult. A general radiograph of the chest sometimes fails to reveal the injury. A localized view may be of assistance. This can be done by two methods. The cassette is placed in contact with the site of greatest pain and compression applied so as to prevent movement of this part of the chest wall. If the patient is then instructed to breathe lightly the part of the ribs in contact with the cassette will remain stationary and the outline of the remainder of the ribs will be blurred owing to the movement. The second method is to diminish the focal skin distance so as to blur the overlying ribs and bring the part of the chest nearest the cassette into focus.

\section{Conclusion}

This summary of the main conditions which may be the cause of a haemoptysis cannot be considered to be complete, but I hope it will have served to show that a radiological examination is an essential part of the investigation of these cases, and that it may be a deciding factor in the diagnosis. It is well known that no examination of the chest is complete to-day without a complementary radiological investigation.

McGibbon, J. E. G., and Baker-Bates, E. T. (1937). British Medical Journal, i, 109.

Pinchin, A. J. Scott, and Morlock, H. V. (1935). Ibid., 2, 332.

Smith, K. Shirley (1938). Quart. J. Med. New Series, 7, 85

Vinson, P. P. (1928). Ann. Oto-rhinol. Laryngol., 37, 675.

\section{PLAY-THERAPY FOR “PROBLEM" CHILDREN}

\author{
BY
}

ETHEL DUKES, L.R.C.P. \& S.

Medical Director, Institute of Child Psychology

The object of this paper is to show the immediate results of treatment and the present condition of 154 of the children who attended the Institute of Child Psychology for varying periods between the years 1930 and 1935 . With the exception of four cases all the children included in the follow-up were treated by the psychological method known as "play-therapy," according to the technique devised by Dr. Margaret Lowenfeld, who started the institute as a small clinic for problem children in 1928.

During the period under survey 247 children were accepted as patients. Of these thirty-two were consultation cases in which the children attended not more than three times and in which periodical advice as to management was all the treatment indicated and given. Although we know that some of these cases are doing well, they have not been included in the chart, as they were not treated by play-therapy. Fourteen patients were discovered to be mentally defective and were rejected; twenty-three cases were immediately transferred to other institutions for various reasons; and in twenty-four cases the parents proved uncooperative soon after acceptance and the patients ceased to attend. The remaining cases, 154 in number, received full treatment and are analysed in the chart below. The eldest child was 17 and the youngest $2 \frac{1}{2}$. They are divided into four categoriesnamely, neurosis, anti-social and behaviour problems, physical complaints, and educational difficulties.

The majority of the children were recommended by school authorities, social agencies, police-court officials, hospital doctors, and private practitioners. The remainder were brought by patients or friends.

\section{Neurosis (76 Cases)}

Under this heading are included cases in which the chief causes for reference were the following: anxiety, night terrors, sleep-walking, excessive or unwarranted fears and inhibitions, nervousness and hypersensitiveness, hysteria, tics and habit spasms, lack of concentration or self-confidence, inability to play, screaming fits, anorexia nervosa, insomnia, and obsessions. In addition to one or more of these symptoms seven suffered from enuresis, nine from speech defect, and fourteen were backward at school.

\section{TREATMENT}

Twenty-seven were treated by play-therapy alone. In addition to play-therapy forty-two had some kind of medical, surgical, or dental treatment for physical disorders discovered on examination, ranging from dental caries to undescended testicles; nine had speech-therapy; and fourteen educational coaching in one or more subjects. Some children needed two or three of these types of treatment.

\section{Anti-social and Behaviour Problems (38 Cases)}

These children were referred to the institute on account of difficulties such as excessive disobedience, temper tantrums, unmanageableness, truancy, vagrancy, lying, pilfering, stealing, excessive bullying, sexual offences, destructiveness, gangsterism, etc. In addition, seven of 
Tahle showing Analysis of Cases

\begin{tabular}{|c|c|c|c|c|c|c|c|c|c|c|c|c|c|c|c|c|c|c|c|}
\hline \multirow{2}{*}{\multicolumn{2}{|c|}{ Homes }} & & \multirow[b]{2}{*}{$\begin{array}{c}\text { No. } \\
\text { of } \\
\text { Cases }\end{array}$} & \multicolumn{5}{|c|}{ Condition on Discharge } & \multicolumn{11}{|c|}{ Present Condition Follow-up } \\
\hline & & & & Well & $\left|\begin{array}{c}\text { Much } \\
\text { Im- } \\
\text { proved }\end{array}\right|$ & $\begin{array}{c}\text { Im- } \\
\text { proved }\end{array}$ & Unad- & $\begin{array}{l}\text { Unco- } \\
\text { opera- } \\
\text { tive } \\
\text { after } \\
\text { some } \\
\text { Treat- } \\
\text { ment }\end{array}$ & Well & 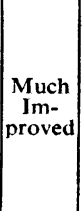 & $\begin{array}{c}\text { Im- } \\
\text { proved }\end{array}$ & $\begin{array}{l}\text { Unad- } \\
\text { justed }\end{array}$ & Dead & Un- & \begin{tabular}{|c|} 
Trans- \\
ferred \\
after \\
Treat- \\
ment \\
to \\
other \\
Insti- \\
tutions
\end{tabular} & $\begin{array}{c}\text { Average } \\
\text { Age }\end{array}$ & $\begin{array}{c}\text { Average } \\
\text { No. of } \\
\text { Attend- } \\
\text { ances. }\end{array}$ & $\begin{array}{c}\text { Average } \\
\text { Months } \\
\text { of } \\
\text { Treat- } \\
\text { ment }\end{array}$ & $\begin{array}{c}\text { A veragc } \\
\text { Intelli- } \\
\text { gent } \\
\text { Quotient }\end{array}$ \\
\hline $\begin{array}{l}\text { Neurosis : } \\
\text { Good } . .\end{array}$ & . & . & 24 & 12 & 8 & 3 & & 1 & 15 & 6 & & 1 & 1 & 1 & & 7.2 & 30.5 & 9 & 116.0 \\
\hline Unsatisfactory & .. & .. & 36 & 12 & 15 & 6 & 2 & 1 & 22 & 3 & 3 & 3 & 1 & 2 & 2 & 8.1 & 33.7 & 9.6 & 104.0 \\
\hline Bad $\quad \ldots$ & .. & .. & 16 & 3 & 7 & 3 & 3 & & 6 & 4 & 1 & 1 & & 2 & 2 & 9.5 & 23.0 & 8.5 & 95.6 \\
\hline Total ... & .. &.. & .76 & 27 & 30 & 12 & 5 & 2 & 43 & 13 & 4 & 5 & 2 & 5 & 4 & & & & \\
\hline $\begin{array}{c}\text { Anti-social behavi } \\
\text { Good } \ldots\end{array}$ & iour : & $\therefore$ & 5 & & 1 & 2 & 2 & & & & 1 & & & 3 & 1 & 9.5 & 26.4 & 7.0 & 99.5 \\
\hline Unsatisfactory & .. & $\cdot$ & 13 & 4 & 5 & 2 & 1 & 1 & 6 & 3 & 1 & & & 2 & 1 & 11.0 & 21.3 & 6.8 & 97.0 \\
\hline Bad & .. & . & 20 & 4 & 6 & 2 & 1 & 7 & 7 & 2 & 1 & 5 & & 3 & 2 & 9.0 & 22.0 & 6.1 & 95.5 \\
\hline Total $\ldots$ & .. &. & 38 & 8 & 12 & 6 & 4 & 8 & 13 & 5 & 3 & 5 & & 8 & 4 & & & & \\
\hline $\begin{array}{l}\text { Medical cases : } \\
\text { Good } \quad .\end{array}$ & .. & .. & 10 & 4 & 3 & 1 & 1 & 1 & 6 & 1 & & 1 & & 1 & 1 & 8.3 & 25.4 & 7.1 & 109.8 \\
\hline Unsatisfactory & .. & .. & 15 & 5 & 8 & & 2 & & 8 & 4 & 1 & 1 & & & 1 & 7.0 & 43.0 & 12.1 & 94.0 \\
\hline Bad .. & .. &.. & 9 & 1 & 3 & 5 & & & 4 & 3 & 1 & & & 1 & & 8.0 & 40.2 & 14.0 & 84.0 \\
\hline Total ... & . &. & 34 & 10 & 14 & 6 & 3 & 1 & 18 & 8 & 2 & 2 & & 2 & 2 & & & & \\
\hline Educational cases & & 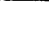 & & & & & & & & & & & & & & & & & \\
\hline Good $\quad \ldots$ & . & .. & 1 & 1 & & & & & 1 & & & & & & & 10 & 21 & 7 & 98 \\
\hline Unsatisfactory & .. & .. & 2 & 1 & 1 & & & & 2 & & & & & & & 11 & 12 & 4 & 105.5 \\
\hline Bad $\quad .$. & $\cdots$ & .. & 3 & & 3 & & & & 1 & 1 & & & & 1 & & 9.7 & 50.0 & 13.0 & 91.5 \\
\hline Total & . & $\ldots$ & 6 & 2 & 4 & & & & 4 & 1 & & & & 1 & & & & & \\
\hline
\end{tabular}

the above suffered from enuresis and five were backward at school.

TREATMENT

Eighteen were treated by play-therapy alone. In addition to play-therapy eighteen had treatment for physical disorders and five had educational coaching.

\section{Physical Complaints (34 Cases)}

These children were referred to the institute on account of some chronic medical disorder, for which, in many cases, previous treatment had been of no avail. The complaints included asthma, eczema, urticaria, fits, functional eye complaints, functional paralysis, muscular incoordination, general debility, pyknolepsy, colitis, vomiting, etc. In some cases there was an underlying neurosis which manifested itself only in this manner, or there was an accompanying neurosis which helped to form a "vicious circle." Eighteen had enuresis, either as the only complaint or in addition to another.

\section{TREATMENT}

Sixteen were treated by play-therapy alone. In addition to play-therapy seventeen had some kind of dental, medical, or surgical treatment and three had educational coaching.

\section{Home Circumstances}

Comprehensive accounts of the home conditions of these children have been obtained, and are graded according to three evaluations: good, unsatisfactory, and bad.

Good.-In these homes the material conditions were good, varying only according to the social position of the family. So far as could be ascertained the emotional relations between the parents were normal. Any psychological mistakes in the nurture of the children were such as spring from a too strong insistence on the ordinary taboos and inhibitions prescribed by convention and a sense of respectability and a too early or rigid training in cleanliness and social behaviour. Symptoms of anxiety neurosis were noticeable in some of the mothers.

Unsatisfactory.- In these homes, though the income was usually sufficient for the needs of the family unless there was temporary unemployment, the psychological conditions were not good. Parental psychoneurosis, bad relations between the parents, broken homes, bad management of the home, adoption and illegitimacy, and gross mismanagement of the children were among the difficult factors in the family situation. A few of these children were now living in homes and hostels, having had bad earlier experiences.

Bad.-Here the conditions were bad in every sense. Poverty, overcrowding, slum conditions, drunkenness. sexual offences, illegitimacy, feeblemindedness, wifebeating, and desertion were prevalent.

The figures show that in the neurosis, the anti-social, and the medical groups (the educational group is too small for comparison) there is a correlation between the type of home, the complaint, and the average intelligence quotient. The average intelligence quotient was lowest in the "bad" type of home in all three groups.

In the anti-social group the numbers admitted for antisocial behaviour vary directly with the type of home. being smallest in the "good" type. From the "bad" type of home came 52.6 per cent. of the anti-social cases: from the "unsatisfactory" type 34.2 per cent.; from the "good" type only 13.2 per cent. 
In the neurosis group the figures were 21 per cent. from the "bad" type of home; 47.3 per cent. from the "unsatisfactory" type ; and 31.5 per cent. from the "good" type. Neustatter (1938) showed that poor social conditions did not necessarily produce neurosis in children unless there were symptoms of it in the parents. The above figures seem to confirm his findings and to suggest that delinquency and crime are more likely to be the end-results in the "bad" type of home. It is interesting to note that the highest percentage of neurosis cases came from the more comfortable homes where psychological conditions were bad.

The results of treatment, the length of time taken, and the number of attendances necessary do not seem to bear any relation to the type of home. Just as good and enduring results seem to have come about in cases from "bad" homes as in those from the other two types. This suggests that the direct method of play-therapy can be successful in helping the child to overcome his difficulties without the necessary aid of environmental change.

\section{Immediate Results of Treatment}

Many of those placed under "much improved" on discharge might have been labelled "well "-that is, free from the symptoms for which they were referred, with no development of other symptoms indicating that adjustment had not been reached. But, as we felt that consolidation was still necessary after they left, they were designated in the case sheets "much improved."

\section{Present Condition of Patients}

It is satisfactory to report that many of the "much improved" cases can now be labelled "well," and as far as can be judged are completely normal. Under the heading "unadjusted" are four anti-social cases, one of whom is in Borstal and two are in Home Office schools. These cases were prematurely removed from the clinic by their parents, who became uncooperative after the children had had a certain amount of treatment. They all came from "bad" homes. One case of neurosis from a "bad" home is now in Borstal. The present condition of the 154 patients is as follows:

\begin{tabular}{|c|c|c|c|}
\hline $\begin{array}{lll}\text { Well } & \ldots & \ldots\end{array}$ & $\begin{array}{ll}. . & . .\end{array}$ & .. & .. \\
\hline Improved and much & improved & . & .. \\
\hline Unadjusted $\quad \ldots$ & $\ldots \quad \ldots$ & .. & .. \\
\hline Dead or not traced & & .. & .. \\
\hline Transferred to other & - institutions & . & .. \\
\hline
\end{tabular}

This is not a large number, but the method of treatment was then new and experimental, and fewer cases were taken than now. At the Institute of Child Psychology attention is more intensively concentrated on the treatment of the patient and less on the alteration of environmental conditions, and consequently the period of treatment is longer and the attendances more frequent than in other clinics treating similar cases by different methods. The social worker does not visit the home more than once, and the aim of the treatment is to help the child to overcome his own problems rather than to remove difficulties from his path. On the other hand, the constant attendance of the mothers at the centre and the influences exerted upon them both in the social workers' department and in the parents' department doubtless have an effect through the mother upon the home environment.
The clinic is open twice weekly for sessions of two hours each, and the majority of the children attend twice a week until improvement is well established, when the intervals are extended until attendance ceases altogether, except for reporting purposes. Every child receives a medical examination on entrance and at periodic intervals. Where necessary medical or surgical treatment is arranged for, in consultation with the family physician if there is one, in order to help the child to become as physically fit as possible. Simple medical treatment is given at the institute itself if the parents are too poor to pay for private medical attendance. In some cases convalescent holidays are arranged for varying periods. In certain medical disorders, however, where a psychological origin is suspected, no medical treatment at all is advised or given. As an adjunct to play-therapy and also in the interests of physical fitness, the physical re-education and rhythm department is of great help in treatment. The formation of a parents' department, in charge of a medical psychotherapist, though primarily for the purpose of helping the parents with their own difficulties, is doubtless responsible for the fact that once the child's treatment is established a large percentage of the mothers remain co-operative throughout, however long it takes.

Acknowledgments are due to Dr. Elspeth Macleod, tutor, Institute of Child Psychology, for the help she has given with some of the cases.

REFERENCE

Neustatter, W. Lindesay (1938). Lancet, 1, 1436.

\section{TREATMENT OF GONORRHOEA WITH ULERON}

\author{
BY \\ D. F. WALSH, M.B., B.Ch. \\ Surgeon Lieutenant Commander, R.N.
}

The following is a record, with observations, of fortythree cases of gonorrhoea, of which twenty-one had received routine treatment for at least six weeks prior to having uleron.

Uleron is one of the newer compounds evolved in the endeavour to obtain a drug, possessing the lowest possible toxicity, which would influence the largest number of bacterial diseases apart from streptococcal infections. It has the formula:

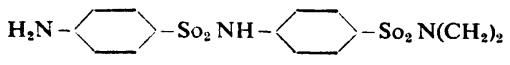

It is one of three closely allied compounds, which only differ by substitutions in the final sulphonamide group, and which have been found to exert a more favourable influence in gonococcal infections than any of the other thousand compounds investigated.

Uleron is manufactured by Messrs. Bayer, who kindly put a supply at my disposal. I was told quite frankly that they could make no definite claims for uleron, which was still under trial; that I might find it a complete failure; and that neither its dosage nor its non-toxicity was established. It had been tried out in some clinics in Germany, and a translation of the report by Grütz, "New Foundations for the Treatment of Gonorrhoea," an advance proof of Fischer's "New Methods of Treatment of Gonorrhoea," and Felke's "On the Chemotherapy of Gonorrhoea" constituted the available literature at that time. These three workers were most enthusiastic about the therapeutic value of the new compounds. They claimed their advent as the greatest advance ever made 